\title{
Imaging congenital heart disease in adults
}

\author{
P J KILNER, MD, PhD
}

Cardiovascular Magnetic Resonance Unit, Royal Brompton Hospital, London, UK

\begin{abstract}
Transthoracic echocardiography is the first-line modality for cardiovascular imaging in adults with congenital heart disease (ACHD). The windows of access that are possible with transthoracic echocardiography are, however, rarely adequate for all regions of interest. The choice of further imaging depends on the clinical questions that remain to be addressed. The strengths of MRI include comprehensive access and coverage, providing imaging of all parts of the right ventricle, the pulmonary arteries, pulmonary veins and aorta. Cine images and velocity maps are acquired in specifically aligned planes, with stacks of cines or dynamic contrast angiography providing more comprehensive coverage. Tissues can be characterised if necessary, and MRI provides relatively accurate measurements of biventricular function and volume flow. These parameters are important in the assessment and follow-up of adults after repairs for tetralogy of Fallot or transposition of the great arteries and after Fontan operations. The superior spatial resolution and rapid acquisition of CT are invaluable in selected situations, including the visualisation of anomalous coronary or aortopulmonary collateral arteries, the assessment of luminal patency after stenting and imaging in patients with pacemakers. Ionising radiation is, however, a concern in younger patients who may need repeated investigation. Adults with relatively complex conditions should ideally be imaged in a specialist ACHD centre, where dedicated echocardiographic and cardiovascular MRI services are a necessary facility. General radiologists should be aware of the nature and pathophysiology of congenital heart disease, and should be alert for previously undiagnosed cases presenting in adulthood, including cases of atrial septal defect, aortic coarctation, patent ductus arteriosus, double-chambered right ventricle and congenitally corrected transposition.
\end{abstract}

DOI: $10.1259 / \mathrm{bjr} / 74240815$

(C) 2011 The British Institute of Radiology
This article provides an overview of the role of imaging in the assessment of adults with congenital heart disease (ACHD). Congenital malformations of the heart affect at least $1 \%$ of newborn infants [1]. Without intervention, the prognosis for more complex disease forms is poor. However, advances in paediatric cardiology and cardiac surgery made over the past few decades have revolutionised patient management, and the majority of patients now survive into adulthood. This has led to new challenges as increasing numbers of congenital heart patients pass into the care of adult cardiac services. The need for expert knowledge to allow the appropriate investigation of highly variable anatomy and pathophysiology, and to manage this patient group, has led to the expansion of the cardiological subspecialty of adult congenital heart disease [2, 3]. Many ACHD patients will have undergone palliative or reparative surgery during early life. These procedures are rarely curative and life-long follow-up is generally required to optimise the quality and span of life. Many ACHD patients develop arrhythmias secondary to intrinsic conduction abnormalities, surgical interventions or residual haemodynamic lesions. It is important for imaging specialists to understand the palliative shunts, surgical repairs and reconstructive procedures used, some

Address correspondence to: Dr Philip Kilner, Cardiovascular Magnetic Resonance Unit, Royal Brompton Hospital, Sydney Street, London SW3 6NP, UK. E-mail: p.kilner@rbht.nhs.uk

The author is funded by the British Heart Foundation. of which entail techniques that have changed greatly over the years $[4,5]$.

\section{Where should patients with ACHD be imaged?}

For those ACHD patients who are likely to need further surgery or other interventions to treat arrhythmia or haemodynamic lesions, it is recommended that imaging is undertaken in the specialist centre where they are being followed up [6]. Examples include patients with re-stenosis or aneurysm formation after repair of aortic coarctation, patients with pulmonary regurgitation after repair of tetralogy of Fallot (ToF), those who have undergone surgery for transposition of the great arteries (TGA) or for a functionally single ventricle, and patients with a variety of other more unusual or complex conditions. Relevant experience is needed to acquire and interpret images in these patients, especially those acquired by echocardiography and cardiovascular MRI, and collaboration between the imaging specialists, cardiologists and surgeons in such centres contributes to improved understanding of the complex and variable conditions they have to deal with. Large imaging data sets that include acquisitions of various types are best reviewed interactively in the context of multidisciplinary discussion of clinical management.

Having said that, general radiologists and cardiac imaging specialists must be able to recognise and appropriately 
investigate previously undiagnosed congenital heart disease that may present in adulthood. At the very least, they must appreciate the nature and potential complications of the main types of congenital heart disease. Besides aortic coarctation as a possible cause of upper limb hypertension, clinicians should be alert to atrial septal defect (ASD) as a possible cause of a dilated right ventricle. Sinus venosus ASD, which may not be directly visible on routine echocardiography, is commonly associated with partial anomalous pulmonary venous drainage. Ventricular septal defect, double-chambered right ventricle (subinfundibular stenosis) and patent ductus arteriosus can all present in adulthood as an audible murmur, through the dilatation of a chamber or as entities on a chest radiograph. Congenitally corrected transposition (atrioventricular and ventriculoarterial discordance) can also remain undiagnosed until adulthood, and it is important to be able to distinguish a morphologically right ventricle (RV) from a left ventricle (LV) on cross-sectional images.

\section{Issues specific to congenital heart disease}

Functional assessment of the right heart represents an important aspect of imaging in ACHD patients [7]. The free wall and apical regions of the RV are normally extensively trabeculated, with relatively little compact myocardium. The pathophysiology of a subpulmonary RV that is volume loaded by pulmonary or tricuspid regurgitation differs markedly from that of a systemic LV with an incompetent valve. This is not only because ventricular form and structure differ, but also because of the relative situations of the ventricles with respect to the high systemic and the low pulmonary resistances. The LV normally delivers most of the total circulatory work and is connected in series, via the high-resistance systemic and low-resistance pulmonary vasculature, with the less powerful RV. Free pulmonary regurgitation, with little or no effective valve action, may be tolerated without symptoms for decades, although right ventricular dysfunction, arrhythmia and premature death can result. Imaging, with measurements of RV function and pulmonary regurgitation, plays a key role in deciding the nature and timing of re-intervention in such patients.

Additional areas to be addressed by imaging in ACHD include the assessment of stenoses of both outflow tracts (the aorta and pulmonary arteries), the quantification of regurgitation and the identification and quantification of any intracardiac or extracardiac shunts. Flow measurement by phase-contrast MRI plays a particular role here, with velocities encoded through planes transecting the ascending aorta and/or main pulmonary artery. Such measurements can be subject to error, which can be minimised by avoiding unnecessarily high velocity encoding ranges and ensuring that the region of measurement is as close as possible to the magnet isocentre. If still problematic, correction by subtraction of a corresponding subsequent "flow" acquisition in a static phantom is recommended [8].

Adequate non-invasive imaging can avoid the need for diagnostic catheterisation in most ACHD patients, and can shorten the procedure time should invasive investigation or intervention be required. The costs of imaging need to be weighed against the potential costs of lessinformed management.
In complex malformations, the cardiovascular interconnections should be established and described methodically, which is best done according to sequential segmental analysis $[9,10]$. The structures of the atrial and ventricular cavities have typical left- and right-sided forms, as do the upper abdominal organs and the bronchi. "Left" and "right" are used in this context to indicate morphological characteristics rather than position. A patient may thus be said to have a "left-sided right ventricle", identified as morphologically right by virtue of its moderator band, additional coarse trabeculations arising from the septum and, in most cases, a myocardial infundibulum encircling its outflow tract.

Sequential segmental analysis begins by stating the atrial arrangement (situs), which can be "usual" (in Latin, atrial situs solitus) (i.e. a right atrium on the right and a left atrium on the left) or "inverted" (situs inversus), or there can be bilateral duplication of one type of atrium, known as right or left atrial "isomerism". Isomerism is generally associated with accompanying malformations. In almost all cases, the atrial arrangement corresponds to that of the bronchi, and usually to that of the abdominal organs. Thus, the visibility of a long pre-branch segment with passage inferior to the corresponding pulmonary artery of a "left" main bronchus, or of a shorter pre-branch segment with passage superior to the corresponding pulmonary artery of a "right" main bronchus, gives a useful indication of the atrial morphology on the same side, as do the two lobes of a "left" lung and the three lobes of a "right" lung.

Atrioventricular and ventriculo-arterial connections are described as concordant (e.g. right atrium (RA) to RV, or LV to aorta) or discordant (e.g. left atrium (LA) to RV). TGA is synonymous with discordant ventriculo-arterial connections, and the transposed outflow tracts tend to lie almost parallel to one another rather than curving across each other in the usual manner. It is also possible for both inflow or both outflow valves to connect predominantly with one ventricle (a double-inlet or a double-outlet ventricle) or for one of the atrioventricular connections to be absent, as in tricuspid atresia.

\section{Overview of the main non-invasive imaging modalities}

The different non-invasive modalities are, to a large extent, complementary (Table 1). More than one modality is likely to be needed to address all of the relevant clinical questions, particularly in more complex cases.

\section{Chest radiography}

Postero-anterior with or without lateral chest radiographs provide a valuable, inexpensive and inclusive single-image overview of the heart, mediastinum, pulmonary vessels, lung fields and thoracic skeleton, all of which are potentially relevant in ACHD.

\section{Transthoracic echocardiography}

Transthoracic echocardiography (TTE) is the first-line cardiovascular imaging modality in ACHD patients, 
Table 1. The relative strengths and limitations of the three main imaging modalities used for adults with congenital heart disease (ACHD)

\begin{tabular}{|c|c|c|c|}
\hline & Echocardiography & MRI & Ст \\
\hline $\begin{array}{l}\text { Methodological } \\
\text { strengths }\end{array}$ & $\begin{array}{l}\text { Real time } \\
\text { Portable } \\
\text { Local velocity measurements } \\
\text { M-mode traces and 3D } \\
\text { Suitable for operating theatre } \\
\text { and during exercise } \\
\text { Free of ionising radiation }\end{array}$ & $\begin{array}{l}\text { Versatile } \\
\text { Unrestricted access } \\
\text { Multislice cine coverage } \\
\text { Biventricular function } \\
\text { Volumetric flow measurement } \\
\text { Tissue characterisation } \\
\text { Dynamic angiography } \\
\text { Free of ionising radiation }\end{array}$ & $\begin{array}{l}\text { Excellent spatial resolution } \\
\text { 3D visualisation and access } \\
\text { Short acquisition time } \\
\text { Calcium seen well } \\
\text { Lumen generally seen within stents }\end{array}$ \\
\hline $\begin{array}{l}\text { Clinical strengths } \\
\text { in ACHD }\end{array}$ & $\begin{array}{l}\text { Applicable in almost all cases } \\
\text { Strong for valve disease, } \\
\text { jet velocities, septal } \\
\text { defects and vegetations }\end{array}$ & $\begin{array}{l}\text { Many applications, notably } \\
\text { in aortic coarctation, Fallot's } \\
\text { tetralogy, shunts, TGA and } \\
\text { complex cases }\end{array}$ & $\begin{array}{l}\text { Visualisation of coronary and } \\
\text { collateral arteries } \\
\text { Visualisation of conduits and stents } \\
\text { Visualisation of associated lung } \\
\text { pathology }\end{array}$ \\
\hline $\begin{array}{l}\text { Methodological } \\
\text { limitations }\end{array}$ & $\begin{array}{l}\text { Limited windows, angles } \\
\text { and depth of access } \\
\text { Not suitable for volumetric } \\
\text { flow measurement }\end{array}$ & $\begin{array}{l}\text { Image slices are relatively thick } \\
\text { Acquisition is relatively time } \\
\text { consuming and expensive } \\
\text { Pacemakers are generally } \\
\text { regarded as a contraindication }\end{array}$ & $\begin{array}{l}\text { lonising radiation } \\
\text { No flow measurement } \\
\text { Limited cine visualisation }\end{array}$ \\
\hline $\begin{array}{l}\text { Clinical weaknesses } \\
\text { in ACHD }\end{array}$ & $\begin{array}{l}\text { Cannot usually access all } \\
\text { parts of the RV, pulmonary } \\
\text { arteries, pulmonary veins or } \\
\text { aorta }\end{array}$ & $\begin{array}{l}\text { Cannot reliably exclude patent } \\
\text { foramen ovale or a small ASD, } \\
\text { detect mobile vegetations in } \\
\text { endocarditis or measure tricuspid } \\
\text { regurgitation jet velocity for RV } \\
\text { pressure estimation }\end{array}$ & $\begin{array}{l}\text { Relatively limited functional } \\
\text { information. Unsuitable for } \\
\text { repeated follow-up studies } \\
\text { because of radiation }\end{array}$ \\
\hline
\end{tabular}

3D, three-dimensional; ASD, atrial septal defect; RV, right ventricle; TGA, transposition of the great arteries.

being particularly suitable for the real-time interrogation of relatively small, thin and mobile intracardiac structures, leaflets, septa, jets and infective vegetations, which may be less well seen on MRI. In the majority of patients, TTE allows the evaluation of cardiac anatomy (i.e. orientation and veno-atrial, atrioventricular and ventriculo-arterial connections), the morphology of cardiac structures, ventricular and valvular function, the presence of shunt lesions and haemodynamic function (e.g. severity of regurgitation and evaluation of shunts and velocities across obstructions). Nevertheless, the suboptimal penetration of ultrasound poses the chief limitation of TTE, especially in adults after cardiovascular surgery. Moreover, TTE does not offer MRI's repertoire of tissuecontrast options, with or without contrast agent, and lacks MRI's unrestricted fields of view and frame of spatial reference with respect to the axes of the patient's body. Doppler techniques measure only velocities directed to or from the transducer and not those across or through the sector of the image. Nevertheless, Doppler velocity recording has the advantage over MRI of being able to measure the velocities of narrow tricuspid or pulmonary regurgitant jets, which allows the estimation of pressure differences between RV and RA in systole or between the pulmonary artery (PA) and RV in diastole. This is rarely practicable by MRI velocity mapping, mainly owing to the size and shape of voxels relative to the limited coherent cores of such jets.

\section{Transoesophageal echocardiography}

Transoesophageal echocardiography (TEE) has the advantage of access to more posterior parts of the heart, particularly for three-dimensional (3D) visualisations of the valves, and is suitable for intra-operative use. The main disadvantages are its relatively invasive nature, generally requiring sedation or anaesthesia, and its limited field of view. The ability of TEE to evaluate extracardiac anatomy is limited and the alignment of the Doppler beam with unusually orientated flow jets can be challenging. TEE suffers from many of the limitations of TTE and is generally less acceptable than MRI for serial follow-up investigation.

\section{Cardiovascular MRI}

This modality is not restricted by body size or poor acoustic windows and is versatile, offering a repertoire of velocity-mapping and tissue-contrast options, without any ionising radiation [11, 12]. The versatility presents challenges, however, and consistency of methods between studies or between centres should not be assumed. MRI is widely regarded as the gold standard for measurements of both right and left ventricular volumes, although these analyses take time and require rigorously consistent methods of acquisition and measurement that may be difficult to maintain in practice $[13,14]$. Unlike Doppler ultrasound, MRI velocity mapping allows the measurement of flow through planes transecting a large vessel for the calculation of regurgitant or shunt flow volumes [15]. First-pass adenosine stress myocardial perfusion imaging can be performed by MRI using gadolinium contrast. The freedom from ionising radiation makes MRI an appealing choice for the relatively young patient group with congenital heart disease [16]. This includes patients with TGA treated by arterial switch, which entails reimplantation of the coronary arteries. Late gadolinium enhancement can give information on myocardial fibrosis 
in both the RV and LV [17]. MRI offers robust spatial localisation with respect to the axes and dimensions of the patient's body.

Pacemakers and implantable defibrillators are currently regarded as contra-indications for cardiac MRI. Arrhythmias tend to degrade the quality of MRI images, cine images generally being reconstructed from electrocardiogram (ECG)-gated acquisition during a breath-hold.

\section{Computed tomography}

CT offers excellent spatial resolution and relatively unrestricted access in much shorter acquisition times than MRI $[18,19]$. It is well suited for imaging the epicardial coronary arteries and their relations to adjacent structures or conduits [20]. ECG-gated cine CT allows measurements of biventricular size and function, albeit at a lower temporal resolution than MRI and subject to adequate opacification of each intraventricular blood volume $[21,22]$. CT provides an alternative to MRI in patients with a pacemaker or implantable cardioverter-defibrillator (ICD). The main drawback of CT is exposure to ionising radiation and its associated risk of cancer [23-26]. This risk is dose, age and gender dependent, and makes repeat CT examinations or studies in young patients unattractive. Other drawbacks compared with MRI include less versatile tissue contrast and an inferior ability to evaluate cardiovascular physiology, although the 3D spatial resolution provided by CT is unrivalled.

\section{Cardiac catheterisation}

Although used less for diagnosis since improved noninvasive approaches have became available, catheterisation has roles in the calculation of pulmonary resistance, assessment of coronary artery disease and for percutaneous interventions using balloons, stents, occlusion devices or implantable valves, notably for placement of a valve in a pre-existing but regurgitant RV to PA conduit.

\section{Specific categories of congenital heart disease}

\section{Aortic coarctation}

The majority of surgical repairs and catheter interventions for aortic coarctation have satisfactory outcomes, but a mild degree of residual aortic narrowing is common and it is important to screen periodically for re-stenosis or aneurysm formation. Aneurysms may occur after attempted balloon dilatation, or after repairs by a prosthetic patch-an approach rarely, if ever, used now. Aortic coarctation may be associated with abnormal properties of the wall of the aorta. A functionally bicuspid aortic valve is present in at least $50 \%$ of cases, and is more prone to progressive stenosis and/or to regurgitation than a normal valve. Echocardiography from a suprasternal window can usually provide a Doppler trace of jet flow through the residual coarctation, enabling an assessment of the presence or absence of diastolic prolongation of forward flow (a "diastolic tail"), which can be a telling sign of significant obstruction [27]. However, two-dimensional echo rarely provides full visualisation of the repaired region in adults. Because repeated imaging is likely to be needed through the course of a lifetime, MRI is probably the modality of choice for assessment every few years, or more frequently if there is specific cause for concern [28]. An exception is after deployment of a stent, when at least one contrast-CT study provides better assessment of the in-stent lumen and any possible aneurysm formation in the vicinity of the stent [29]. Berry aneurysms of the circle of Willis or other cerebral vessels occur in up to $10 \%$ of patients with coarctation that bears the risk of rupture [30]. Rupture of a cerebral aneurysm is associated with high mortality, and hence screening for cerebrovascular aneurysms by an additional MRI study may be advisable if symptoms develop.

\section{Valve disease}

Echocardiography remains the first line of investigation in cases of heart valve disease [31, 32], but MRI can contribute to the measurement of regurgitation and to the assessment of myocardial or other pathology associated with this disease. In patients with bicuspid aortic valve, MRI allows the assessment of any ascending aortic ectasia, aneurysm or dissection. Regurgitant or stenotic jets are visible on cine imaging, although their appearances depend on the jet size and characteristics and on the relative location and orientation of the imaging slice. The visible extent of a jet does not necessarily relate to the severity of a lesion. Planimetry of an orifice, or of the crosssection of the jet immediately downstream of the orifice, by cine MRI is feasible in some but not all cases, depending on the structure of the jet and the relative thickness and location of the imaging slice. MRI jet velocity mapping can contribute to the quantification of stenosis, but velocities may be underestimated if the slice is not optimally located or if the coherent core of the jet is too narrow or too fragmented to contain several whole voxels. An appropriately aligned and encoded in-plane jet velocity acquisition may be helpful in locating the region of highest velocity prior to through-plane velocity measurement. For each of these applications, it is important to bear in mind the voxel dimensions, in particular the slice thickness, relative to the shape and orientation of a jet, and the potential for velocity underestimation owing to partial volume averaging. Quantification of regurgitation of the inflow valves by MRI is feasible. In the case of a single-valve lesion, ventricular stroke volume difference is used. Alternatively, regurgitations can be quantified by subtracting the outflow volume, measured by mapping velocities through a plane transecting the relevant great artery, from the corresponding ventricular stroke volume. For identification of tethering, prolapse or failure of coaptation of all parts of the mitral (or tricuspid) leaflets, a contiguous stack of cine images aligned perpendicular to the central part of the line of coaptation is recommended $[33,34]$.

\section{Marfan syndrome}

Measurement of the aortic root, of the ascending aorta and its branches and of any aortic regurgitation are likely to be needed periodically for Marfan syndrome patients. 
Hence, MRI is likely to be the modality of choice unless echo windows are considered to be adequate in a particular individual. The LV and mitral valve can be assessed by either echo or MRI. It is important to check for aortic dissection, which may be small and focal [35]. MRI of the lumbosacral spine may be used to identify dural ectasia [36].

\section{Ebstein anomaly and tricuspid regurgitation}

The chest radiograph gives an excellent overview of heart size. Marked dilatation of the RA and RV generally reflects severe tricuspid regurgitation in Ebstein anomaly. Echocardiography allows visualisation of the tricuspid valve and any regurgitation. In Ebstein anomaly, the septal leaflet, particularly its more inferior parts, is apically displaced with "atrialisation" of the basal part of the RV. In some severe cases, the tricuspid valve plane can be rotated to lie in an almost horizontal plane beneath a dilated RV outflow tract. Such malformation is even better

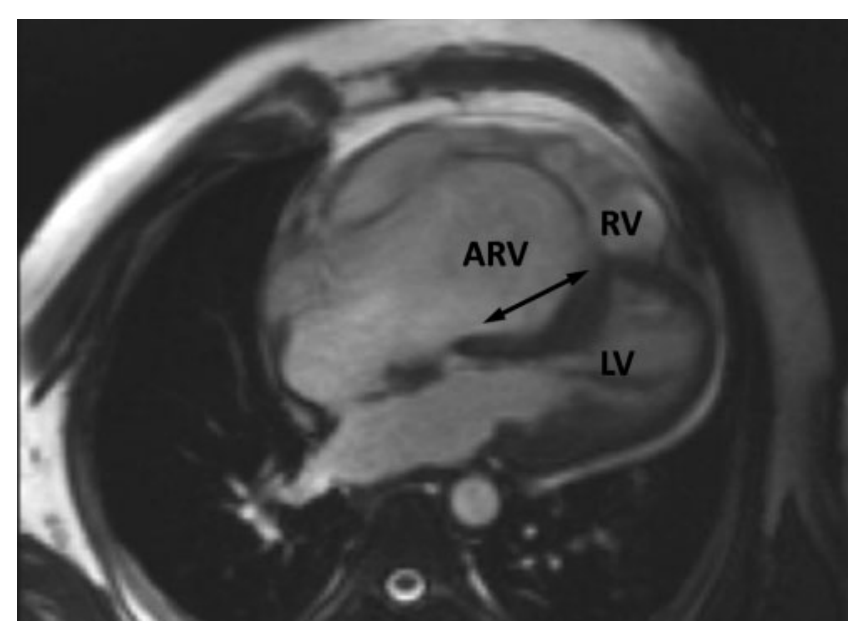

(a)

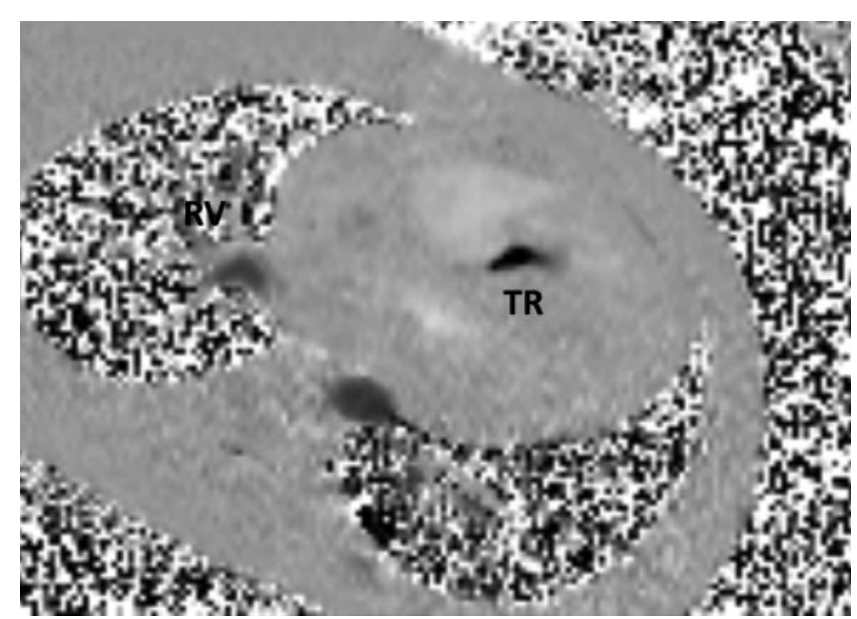

(c) visualised by MRI, using stacks of transaxial and short axis cines, and four chamber cines and an oblique coronal (or $R V$ vertical long axis) cine to show the displacement of the inferior insertion of the tricuspid valve (Figure 1). The severity of tricuspid regurgitation can be assessed using through-plane MRI velocity mapping, the velocity encoding range typically set at $250 \mathrm{~cm} \mathrm{~s}^{-1}$, to depict the crosssection of the regurgitant stream through a plane transecting the jet immediately on the atrial side of the defect. A regurgitant jet cross-section, reflecting the regurgitant defect, of $6 \times 6 \mathrm{~mm}$ or more can be regarded as severe. An ASD resulting from the distension and gaping of a patent foramen ovale is present in about $50 \%$ of adult Ebstein patients, and should be sought by echo or by an MRI atrial short-axis cine stack.

\section{Repaired Tetralogy of Fallot}

Important issues in the relatively large subgroup of patients who have undergone surgical repair of ToF are

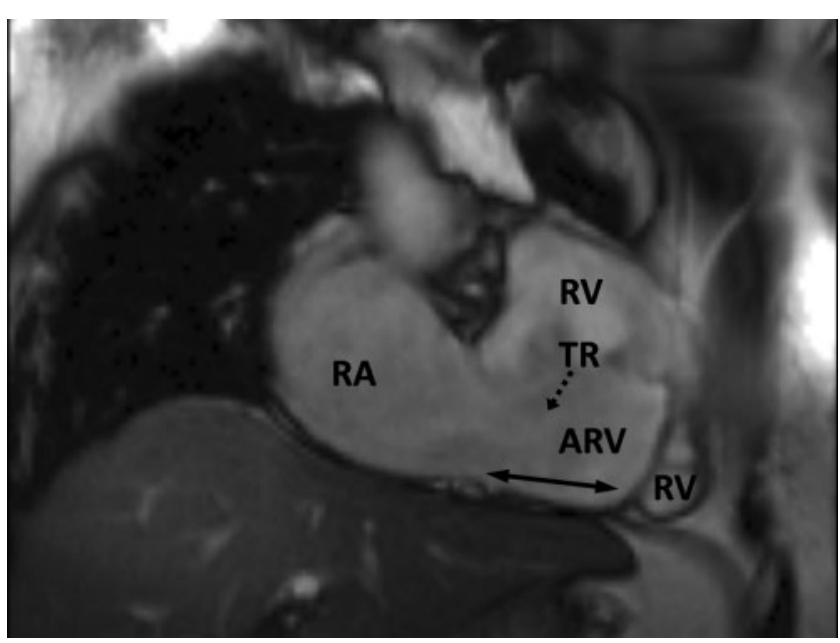

(b)

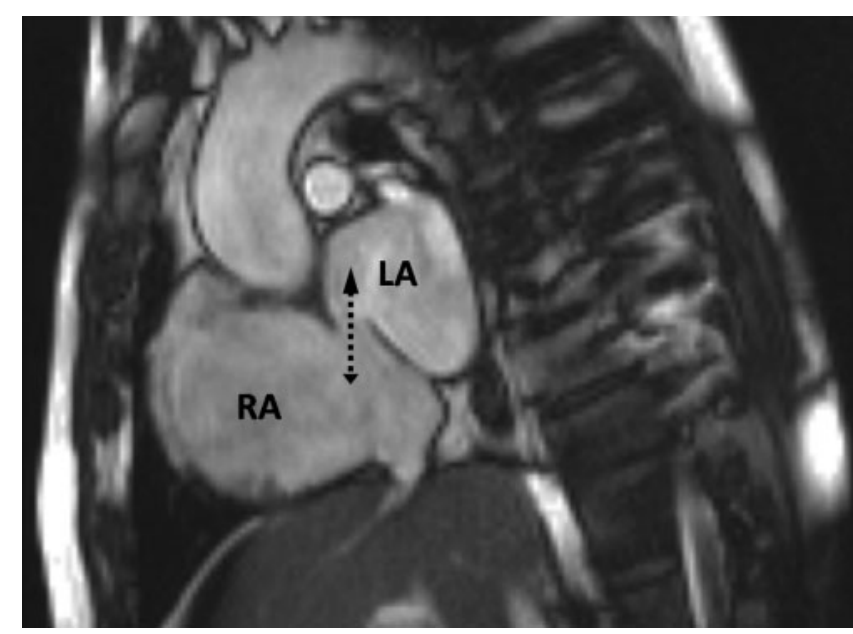

(d)

Figure 1. Features of Ebstein anomaly in a 43-year-old who has not had surgery shown by MRI. (a) Four chamber and (b) oblique coronal cines show the atrialised part of the right ventricle (ARV) relative its functional part (RV, right ventricle). The doubleheaded arrows indicate the extent of apical displacement of the septal and inferior insertions of the tricuspid valve. The dotted arrow indicates the direction of tricuspid regurgitation (TR). (c) Flow (dark) through a velocity mapping plane located to transect the jet (dimensions about $5 \times 14 \mathrm{~mm}$ ) of severe TR. (d) An atrial short axis cine shows a widely patent foramen ovale with bidirectional flow, mainly from the right atrium (RA) to the left atrium (LA). 
the size, regional function and global function of the RV, function of the pulmonary valve, and the patency of the right and left pulmonary arteries [37]. Free or almost free pulmonary regurgitation (PR) is common. Dysfunction of the LV, aortic dilatation, tricuspid regurgitation and a residual ventricular septal defect (VSD) patch leak are less common problems. Echocardiography can usually address most but rarely all of these, which gives an important role to MRI $[38,39]$. The pathophysiology of PR differs from that of aortic regurgitation. Free PR, with little or no effective valve function, may be tolerated without symptoms for decades and is typically associated with a regurgitant fraction of $\sim 35-45 \%$ [40]. It is often associated with a triphasic pattern of flow in the pulmonary trunk: systolic forward flow, early to mid-diastolic reversal of flow (regurgitation) and then late diastolic forward flow as atrial contraction boosts forward flow though a fully

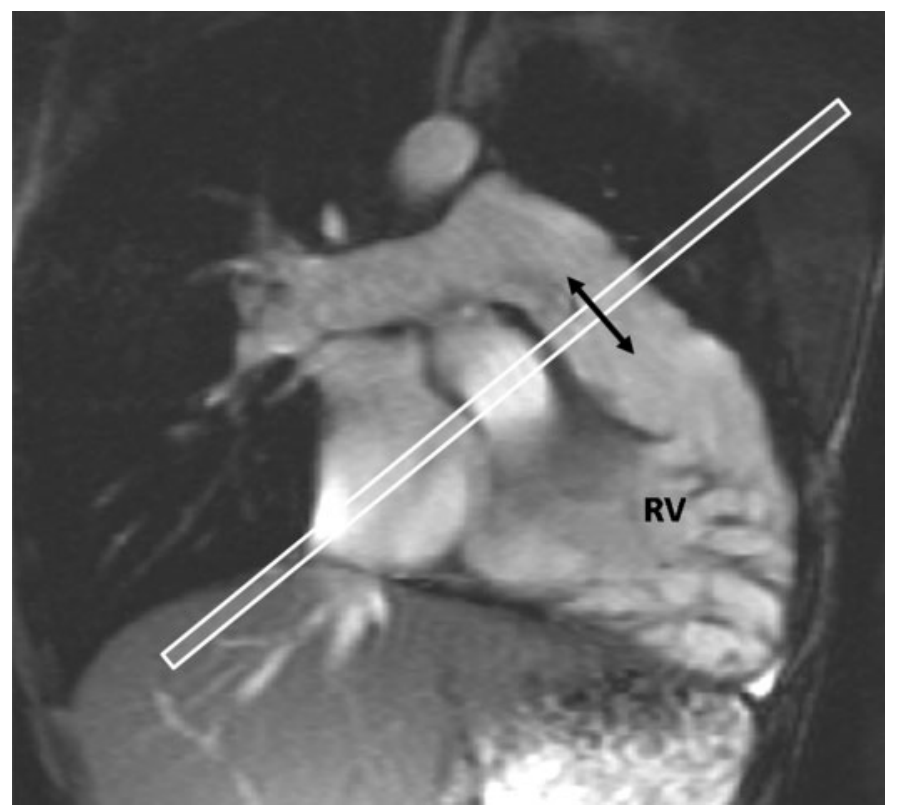

(a) expanded and therefore conduit-like RV (Figure 2). RV dysfunction, arrhythmia and premature death can result. In most centres, pulmonary valve replacement is considered in such patients, but the timing of surgery remains controversial, particularly if the patient is asymptomatic and bearing in mind that a homograft replacement may only function effectively for 15-20 years or less [41-45]. Once a conduit is in position, however, progressive stenosis or regurgitation may be treatable by percutaneous placement of a stented valve within the relatively rigid tube of the conduit [46, 47]. MRI, with contrast angiography, has a role in the selection of patients for such procedures, as has CT, which allows the visualisation of calcium and the clear delineation of the coronary arteries relative to a previously placed conduit.

Even in the absence of an effective pulmonary valve, the amount of regurgitation depends on factors upstream

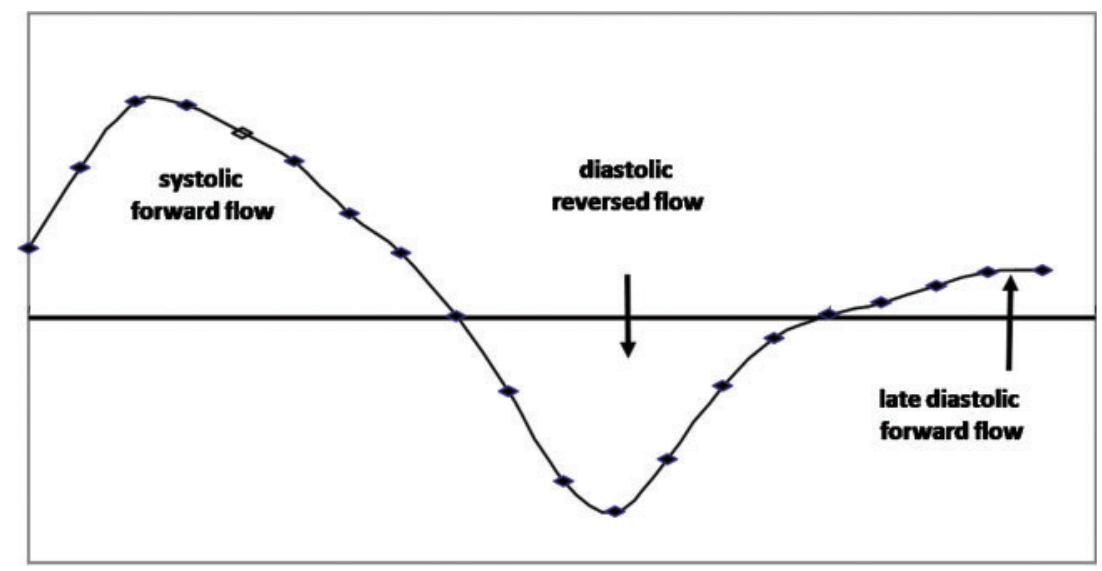

(c)

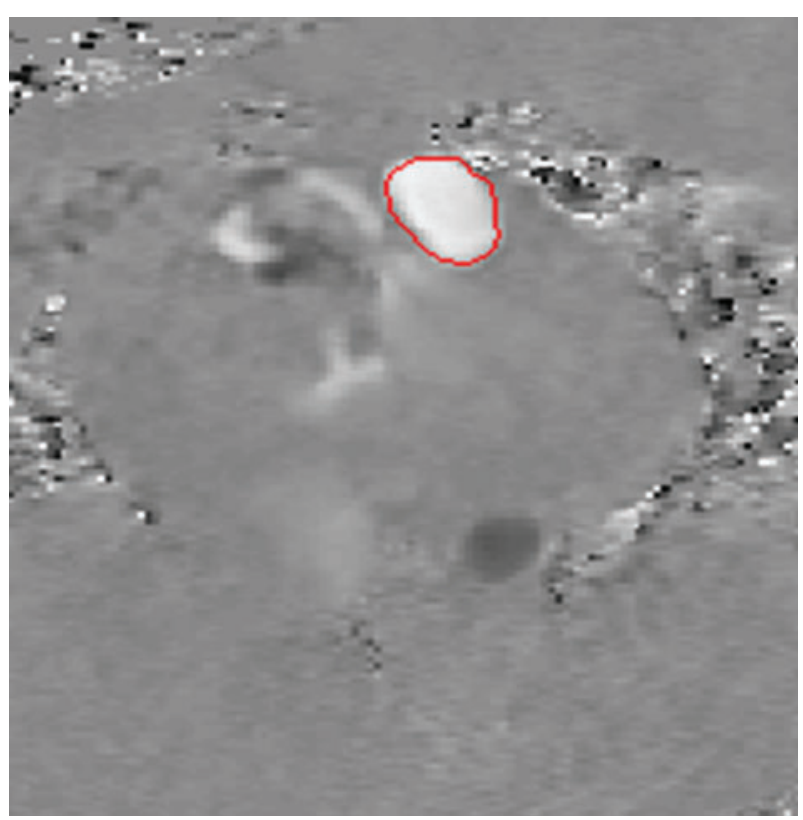

(b) 
and downstream. In occasional cases, the regurgitant fraction can exceed $50 \%$ [48]. This may be attributable to an unusually large and compliant RV, to a large and compliant pulmonary trunk and PA branches whose recoil contributes to the regurgitation [49], to branch PA stenosis or elevated peripheral resistance limiting the distal escape of flow or to combinations of these [50]. In summary, the evaluation of repaired ToF requires thorough assessment of the left and right heart, extending to the branch PAs and ascending aorta.

\section{Double-chambered right ventricle or subinfundibular stenosis}

This disease entity results from obstructing muscular bands or ridges between the hypertrophied body or sinus of the RV and the non-hypertrophied infundibulum. It is usually associated with a VSD into the higher pressure part of the RV, close to the upper part of the tricuspid valve, and may progress during adulthood. It should be possible to identify double-chambered RV echocardiographically, although limited visualisation may make it hard to distinguish between a jet through a VSD, the subinfundibular stenosis and possible infundibular or pulmonary valve stenosis. MRI can help to differentiate between these, although flow through the VSD can be hard to detect. The subinfundibular origin of a DCRV jet, directed into the non-hypertrophied and non-obstructive infundibulum, is generally visible in routine basal short-axis cines (Figure 3) [51].

\section{Major aortopulmonary collateral arteries}

Contrast-enhanced 3D MRI or CT angiography is valuable for delineation of all sources of pulmonary blood supply prior to surgical or transcatheter procedures in patients with major aortopulmonary collateral arteries (MAPCAs) associated with severe pulmonary stenosis or atresia [52].

\section{Pulmonary hypertension}

Doppler echocardiography has the important advantage of being able to measure the velocities, and hence the presumed intercavity pressure difference, of relatively

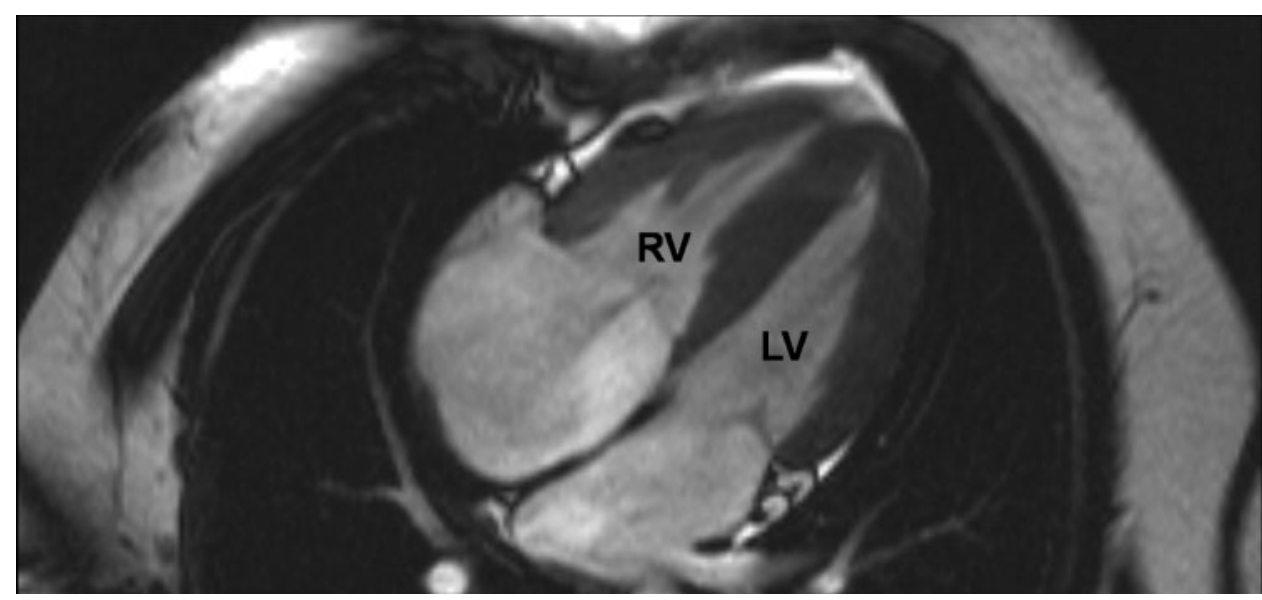

(a)

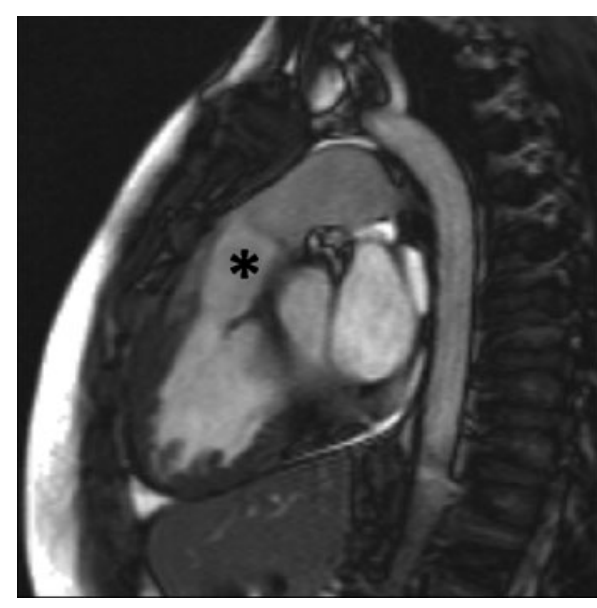

(b)

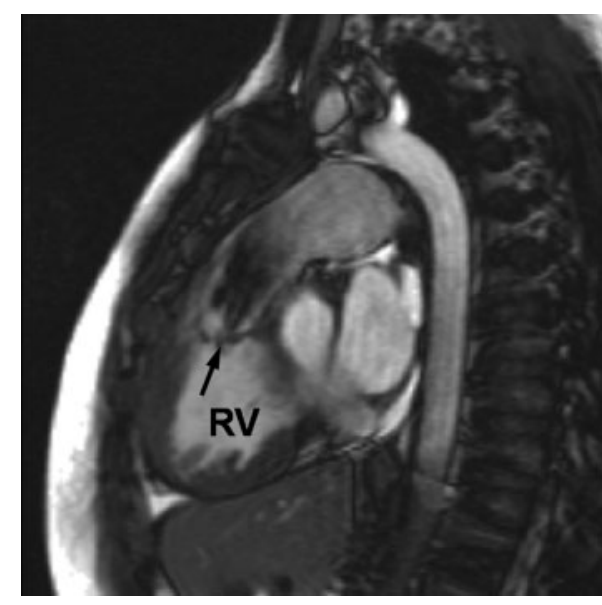

(c)

Figure 3. MRI features of a double-chambered right ventricle (RV), or subinfundibular stenosis, in a 16-year-old who has not had surgery. (a) The RV appears hypertrophied in a four-chamber view, whereas (b) the infundibular region (*) and the pulmonary valve above it are unobstructed. (c) The level of obstruction is seen in a systolic short axis image. The jet from the hypertrophied part of the RV to the infundibular cavity is arrowed. LV, Left ventricle. 
narrow jets of tricuspid or pulmonary regurgitation. This cannot usually be done reliably by MRI. However, MRI does give good visualisation of RV size and function, of RV hypertrophy, of any flattening of the interventricular septum in systole and of the size and relative (lack of) expansion of the main and branch pulmonary arteries. MRI also allows measurement of aortic and pulmonary artery flow for calculation of indexed cardiac output and any shunting. It also enables good visualisation of any anomalies that might contribute to pulmonary hypertension, such as a patent ductus arteriosus (PDA) or VSD [53]. Contrast-enhanced angiography by CT or MRI may be used for the identification of thrombo-embolic disease or aortopulmonary collateral vessels [54]. The shorter acquisition time of CT is an advantage in patients with limited breath-holding ability.

\section{Shunts: ASD, VSD or PDA}

Echocardiography is the modality of choice for visualisation of ASD, VSD or PDA defects, except perhaps for PDA, for which MRI or CT are usually preferable in adults. MRI can also help to clarify the nature of the lesion, the amount of shunting [55], and biventricular size and function, and can detect associated anomalies, notably the possibility of anomalous pulmonary venous drainage [5658]. Ascending aortic flow measured by MRI represents systemic flow $\left(Q_{\mathrm{s}}\right)$ when there is an intracardiac left-toright shunt. However, when the shunt is from the descending aortic arch through a PDA, increased ascending aortic flow is expected that is equivalent to the amount of pulmonary flow $\left(Q_{p}\right)$. The smaller amount of flow measured in the pulmonary trunk will be equivalent to $Q_{\mathrm{s}}[50]$.

\section{Transposition of the great arteries post surgery}

Specialist knowledge is needed for adequate imaging of patients who have TGA. There have been at least three distinct surgical approaches to TGA. Atrial switch operation (Mustard or Senning) was widely used until a decade or so ago. The reconstructed atrial pathways then need to be appropriately imaged, as does the function of the systemic RV [59]. In the past decade, correction by arterial switch has gained favour as it makes the LV the systemic ventricle. However, this procedure, which is usually performed in early infancy, involves re-implantation of the coronaries in the new aortic position and reconnection of the pulmonary trunk to what was an anteriorly located aortic root. This last manoeuvre results in a significant incidence of stenosis of the main, left and right pulmonary arteries, which is best assessed by MRI. A third type of operation for TGA is the Rastelli procedure, which is reserved for patients who also have pulmonary stenosis and a sufficiently large subarterial VSD. After Rastelli operation, assessment of possible stenosis or incompetence of the RV-to-PA conduit, of LV outflow tract (LVOT) flow, of biventricular function and of possible residual shunt are needed. These assessments are probably best achieved by MRI.

\section{Congenitally corrected TGA}

Congenitally corrected TGA involves discordant atrioventricular and discordant ventriculo-arterial connections (Figure 4). If uncomplicated, the affected patients can occasionally remain symptom free and undiagnosed into adulthood. Associated lesions include dextrocardia, a VSD and (sub)pulmonary stenosis. The subaortic RV is prone to dysfunction and regurgitation of its tricuspid valve [60]. Which ventricle is morphologically "right" and which is "left" can be determined by the presence of multiple coarse trabeculations, including the moderator band, arising from the RV but not the LV side of the septum. Each atrio ventricular valve and ventriculo-arterial connection should be visualised by appropriately aligned views.

\section{Fontan operations for functionally single ventricle}

Fontan operations, generally performed in children with only one effective ventricle, result in a fundamental departure from normal circulatory dynamics [5]. The systemic and pulmonary vascular beds are surgically connected in series with one another downstream of the single effective ventricle, so eliminating shunting at the cost of a critically elevated systemic venous pressure that maintains flow through the lungs. Earlier procedures incorporated the RA between the caval veins and PAs, whereas total cavopulmonary connection, connecting inferior vena cava (IVC) flow to the PAs via a lateral tunnel or extracardiac conduit, has been favoured in recent years [5]. Patients who have had this surgery may become subject to arrhythmias, thrombosis, ascites, protein-losing enteropathy and other complications. Imaging by echocardiography and MRI needs specific expertise and is best undertaken in a specialist ACHD centre. Patency of the cavopulmonary pathways, of ventricular and valvular function, and of possible causes of shunting need to be investigated.

\section{Complex congenital heart disease}

MRI allows clarification of anatomy and function, including the presence of anomalous vessels, connections, shunts, stenoses, abdominal situs and possible polysplenia. Comprehensive cardiac, mediastinal and upper abdominal coverage using stacks of contiguous transaxial and coronal cines is recommended, as is dynamic contrastenhanced MRI angiography. Cine images should also be aligned with each inflow and outflow valve, and with any shunt flow, so that connections can be established. Cardiovascular connections should be described according to sequential segmental analysis, as outlined above.

\section{Coronary artery anomalies}

Contrast-enhanced CT is recommended for coronary artery visualisation [61, 62]. The origin and proximal course of the coronary arteries can, in most cases, be visualised by MRI. Image quality depends, however, on meticulous technique, with fat suppression, diaphragm navigator respiratory gating and ECG gating, and suboptimal images are prone to misinterpretation. 


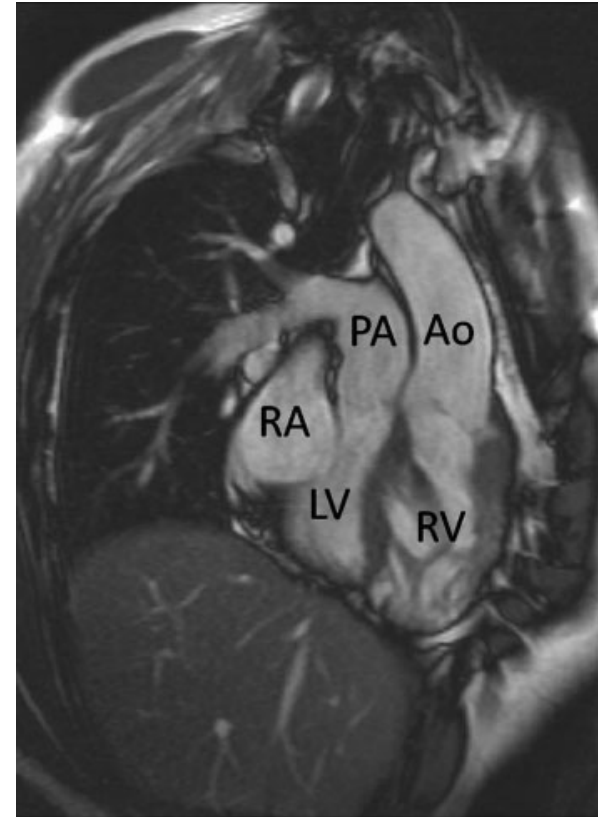

(a)

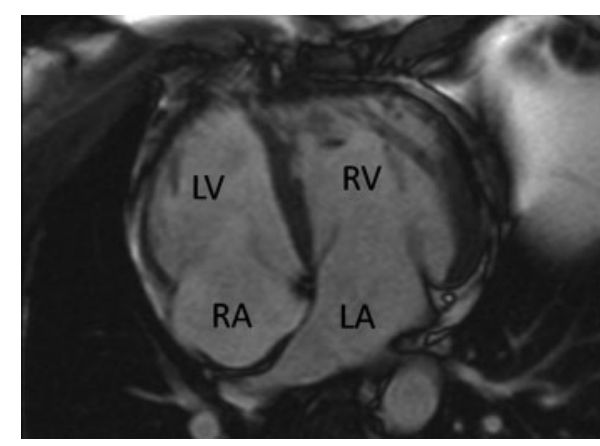

(b)

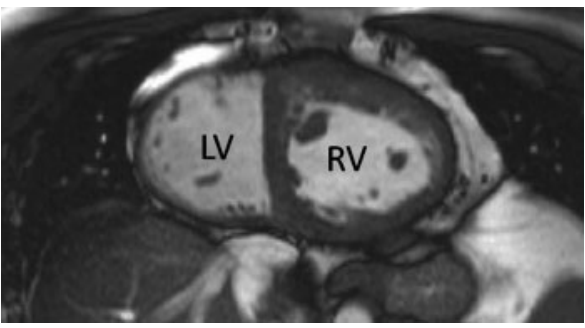

(c)

Figure 4. Unoperated "congenitally corrected" transposition of the great arteries shown by MRI. (a,b) Both the atrioventricular and the ventriculo-arterial connections are discordant. Note the expected apical displacement of the septal insertion of the tricuspid valve of the right ventricle (RV) relative to that of the mitral valve of the left ventricle (LV), and the hypertrophied muscle of the systemic RV. (c) In the mid short axis image, the left ventricular cavity can be identified as the one on the smoother, less trabeculated, side of the ventricular septum. PA, pulmonary artery; Ao, aorta.

\section{Conclusions}

After transthoracic echocardiography, which remains the first-line imaging modality in ACHD, the choice of further imaging depends on the clinical questions that remain to be addressed. Besides tissue characterisation, the strengths of MRI include comprehensive access and coverage, for example by the use of a stack of transaxial cine images or by dynamic contrastenhanced angiography, and the relatively accurate measurements of biventricular function and volume flow. These are particularly useful in the assessment and follow-up of adults after repairs of ToF, aortic coarctation and TGA, and for imaging those who have undergone Fontan operations or with operated or unoperated complex malformations. In the author's view, a dedicated MRI service should be regarded as a necessary facility within a centre specialising in the care of ACHD, with CT being preferable in selected situations. Adults with more complex conditions should ideally be both investigated and managed in a specialist ACHD centre. To realise their full potential and to avoid pitfalls, however, echocardiography, MRI and $\mathrm{CT}$ of ACHD require appropriate training and experience.

\section{Acknowledgment}

Philip Kilner is supported by the British Heart Foundation (PG/08/122) and by the National Institutes of Health Research Cardiovascular Biomedical Research Unit of Royal Brompton and Harefield NHS Foundation Trust and Imperial College.

\section{References}

1. Hoffman JI, Kaplan S. The incidence of congenital heart disease. J Am Coll Cardiol 2002;39:1890-900.

2. Perloff JK, Warnes CA. Challenges posed by adults with repaired congenital heart disease. Circulation 2001;103: 2637-43.

3. Silversides CK, Marelli A, Beauchesne L, Dore A, Kiess M, Salehian O, et al. Canadian Cardiovascular Society 2009 consensus conference on the management of adults with congenital heart disease: executive summary. Can J Cardiol 2010;26:143-50.

4. Warnes CA. Transposition of the great arteries. Circulation 2006;114:2699-709.

5. Gewillig M. The Fontan circulation. Heart 2005;91:839-46.

6. Kilner PJ, Geva T, Kaemmerer H, Trindade PT, Schwitter J, Webb GD. Recommendations for cardiovascular magnetic resonance in adults with congenital heart disease from the respective working groups of the European Society of Cardiology. Eur Heart J 2010;31:794-805.

7. Warnes CA. Adult congenital heart disease importance of the right ventricle. J Am Coll Cardiol 2009;54:1903-10.

8. Chernobelsky A, Shubayev O, Comeau CR, Wolff SD. Baseline correction of phase contrast images improves quantification of blood flow in the great vessels. J Cardiovasc Magn Reson 2007;9:681-5.

9. Anderson RH, Becker AE, Freedom RM, Macartney FJ, Quero-Jimenez M, Shinebourne EA, et al. Sequential segmental analysis of congenital heart disease. Pediatr Cardiol 1984;5:281-7.

10. Van Praagh R, Santini F, Geva T. Segmental situs in congenital heart disease: a fundamental concept. G Ital Cardiol 1990;20:246-53.

11. Knauth Meadows A, Ordovas K, Higgins CB, Reddy GP. Magnetic resonance imaging in the adult with congenital heart disease. Semin Roentgenol 2008;43:246-58.

12. Marcotte F, Poirier N, Pressacco J, Paquet E, Mercier LA, Dore A, et al. Evaluation of adult congenital heart disease 
by cardiac magnetic resonance imaging. Congenit Heart Dis 2009;4:216-30.

13. Koskenvuo JW, Karra H, Lehtinen J, Niemi P, Pärkkä J, Knuuti J, et al. Cardiac MRI: accuracy of simultaneous measurement of left and right ventricular parameters using three different sequences. Clin Physiol Funct Imaging 2007;27:385-93.

14. Maceira AM, Prasad SK, Khan M, Pennell DJ. Reference right ventricular systolic and diastolic function normalized to age, gender and body surface area from steady-state free precession cardiovascular magnetic resonance. Eur Heart J 2006;27:2879-88.

15. Kilner PJ, Gatehouse PD, Firmin DN. Flow measurement by magnetic resonance: a unique asset worth optimising. J Cardiovasc Magn Reson 2007;9:723-8.

16. Prakash A, Powell AJ, Krishnamurthy R, Geva T. Magnetic resonance imaging evaluation of myocardial perfusion and viability in congenital and acquired pediatric heart disease. Am J Cardiol 2004;93:657-61.

17. Babu-Narayan SV, Kilner PJ, Li W, Moon JC, Goktekin O, Davlouros PA, et al. Ventricular fibrosis suggested by cardiovascular magnetic resonance in adults with repaired tetralogy of fallot and its relationship to adverse markers of clinical outcome. Circulation 2006;113:405-13.

18. Cook SC, Raman SV. Multidetector computed tomography in the adolescent and young adult with congenital heart disease. J Cardiovasc Comput Tomogr 2008;2:36-49.

19. Wiant A, Nyberg E, Gilkeson RC. CT evaluation of congenital heart disease in adults. AJR Am J Roentgenol 2009;193:388-96.

20. Bluemke DA, Achenbach S, Budoff M, Gerber TC, Gersh B, Hillis LD, et al. Noninvasive coronary artery imaging: magnetic resonance angiography and multidetector computed tomography angiography: a scientific statement from the American Heart Association committee on cardiovascular imaging and intervention of the council on cardiovascular radiology and intervention, and the councils on clinical cardiology and cardiovascular disease in the young. Circulation 2008;118:586-606.

21. Nicol ED, Gatzoulis M, Padley SP, Rubens M. Assessment of adult congenital heart disease with multi-detector computed tomography: beyond coronary lumenography. Clin Radiol 2007;62:518-27.

22. Nicol ED, Kafka H, Stirrup J, Padley SP, Rubens MB, Kilner PJ, et al. A single, comprehensive non-invasive cardiovascular assessment in pulmonary arterial hypertension: combined computed tomography pulmonary and coronary angiography. Int J Cardiol 2009;136:278-88.

23. Einstein AJ, Moser KW, Thompson RC, Cerqueira MD, Henzlova MJ. Radiation dose to patients from cardiac diagnostic imaging. Circulation 2007;116:1290-305.

24. Sadetzki S. Excess lifetime cancer mortality risk attributed to radiation exposure from pediatric computed tomography scan. Isr Med Assoc J 2007;9:607-9.

25. Einstein AJ, Henzlova MJ, Rajagopalan S. Estimating risk of cancer associated with radiation exposure from 64-slice computed tomography coronary angiography. JAMA 2007;298:317-23.

26. Gerber TC, Carr JJ, Arai AE, Dixon RL, Ferrari VA, Gomes $\mathrm{AS}$, et al. Ionizing radiation in cardiac imaging: a science advisory from the American Heart Association Committee on Cardiac Imaging of the Council on Clinical Cardiology and Committee on Cardiovascular Imaging and Intervention of the Council on Cardiovascular Radiology and Intervention. Circulation 2009;119:1056-65.

27. Nielsen JC, Powell AJ, Gauvreau K, Marcus EN, Prakash A, Geva T. Magnetic resonance imaging predictors of coarctation severity. Circulation 2005;111:622-8.

28. Therrien J, Thorne SA, Wright A, Kilner PJ, Somerville J. Repaired coarctation: a "cost-effective" approach to identify complications in adults. J Am Coll Cardiol 2000;35: 997-1002.

29. Chessa M, Carrozza M, Butera G, Piazza L, Negura DG, Bussadori C, et al. Results and mid-long-term follow-up of stent implantation for native and recurrent coarctation of the aorta. Eur Heart J 2005;26:2728-32.

30. Connolly HM, Huston J 3rd, Brown RD Jr, Warnes CA, Ammash NM, Tajik AJ. Intracranial aneurysms in patients with coarctation of the aorta: a prospective magnetic resonance angiographic study of 100 patients. Mayo Clin Proc 2003;78:1491-9.

31. Bonow RO, Carabello BA, Kanu C, de Leon AC Jr, Faxon $\mathrm{DP}$, Freed MD, et al. ACC/AHA guidelines for the management of patients with valvular heart disease. Circulation 2006;114:e84-e231.

32. Baumgartner $\mathrm{H}$, Hung J, Bermejo J, Chambers JB, Evangelista A, Griffin BP, et al. Echocardiographic assessment of valve stenosis: EAE/ASE recommendations for clinical practice. Eur J Echocardiogr 2009;10:1-25.

33. Gabriel RS, Kerr AJ, Raffel OC, Stewart RA, Cowan BR, Occleshaw CJ. Mapping of mitral regurgitant defects by cardiovascular magnetic resonance in moderate or severe mitral regurgitation secondary to mitral valve prolapse. J Cardiovasc Magn Reson 2008;10:16.

34. Chan KM, Wage R, Symmonds K, Rahman-Haley S, Mohiaddin RH, Firmin DN, et al. Towards comprehensive assessment of mitral regurgitation using cardiovascular magnetic resonance. J Cardiovasc Magn Reson 2008;10:61.

35. Kaemmerer H, Oechslin E, Seidel H, Neuhann T, Neuhann IM, Mayer HM, et al. Marfan syndrome: what internists and pediatric or adult cardiologists need to know. Expert Rev Cardiovasc Ther 2005;3:891-909.

36. Knirsch W, Kurtz C, Häffner N, Binz G, Heim P, Winkler P, et al. Dural ectasia in children with Marfan syndrome: a prospective, multicenter, patient-control study. Am J Med Genet, A 2006;140:775-81.

37. Apitz C, Webb GD, Redington AN. Tetralogy of Fallot. Lancet 2009;374:1462-71.

38. Davlouros PA, Kilner PJ, Hornung TS, Li W, Francis JM, Moon JC, et al. Right ventricular function in adults with repaired tetralogy of Fallot assessed with cardiovascular magnetic resonance imaging: detrimental role of right ventricular outflow aneurysms or akinesia and adverse right-to-left ventricular interaction. J Am Coll Cardiol 2002;40:2044-52.

39. Dorfman AL, Geva T. Magnetic resonance imaging evaluation of congenital heart disease: conotruncal anomalies. J Cardiovasc Magn Reson 2006;8:645-59.

40. Samyn MM, Powell AJ, Garg R, Sena L, Geva T. Range of ventricular dimensions and function by steady-state free precession cine MRI in repaired tetralogy of Fallot: right ventricular outflow tract patch vs. conduit repair. J Magn Reson Imaging 2007;26:934-40.

41. Henkens IR, van Straten A, Schalij MJ, Hazekamp MG, de Roos A, van der Wall EE, et al. Predicting outcome of pulmonary valve replacement in adult tetralogy of Fallot patients. Ann Thorac Surg 2007;83:907-11.

42. Geva T. Indications and timing of pulmonary valve replacement after tetralogy of Fallot repair. Semin Thorac Cardiovasc Surg Pediatr Card Surg Annu 2006;11-22.

43. Frigiola A, Tsang V, Bull C, Coats L, Khambadkone S, Derrick G, et al. Biventricular response after pulmonary valve replacement for right ventricular outflow tract dysfunction: is age a predictor of outcome? Circulation 2008;118:S182-90.

44. Harrild DM, Berul CI, Cecchin F, Geva T, Gauvreau K, Pigula F, et al. Pulmonary valve replacement in tetralogy of Fallot: impact on survival and ventricular tachycardia. Circulation 2009;119:445-51.

45. Oosterhof T, van Straten A, Vliegen HW, Meijboom FJ, van Dijk AP, Spijkerboer AM, et al. Preoperative thresholds for 
pulmonary valve replacement in patients with corrected tetralogy of Fallot using cardiovascular magnetic resonance. Circulation 2007;116:545-51.

46. Lurz P, Coats L, Khambadkone S, Nordmeyer J, Boudjemline $\mathrm{Y}$, Schievano $\mathrm{S}$, et al. Percutaneous pulmonary valve implantation: impact of evolving technology and learning curve on clinical outcome. Circulation 2008;117:1964-72.

47. Frigiola A, Tsang V, Nordmeyer J, Lurz P, van Doorn C, Taylor AM, et al. Current approaches to pulmonary regurgitation. Eur J Cardiothorac Surg 2008;34:576-80.

48. Geva T, Sahn, DJ, Powell AJ. Magnetic resonance imaging of congenital heart disease in adults. Prog Pediatr Cardiol 2003; 17:21-39.

49. Kilner PJ, Balossino R, Dubini G, Babu-Narayan SV, Taylor AM, Pennati G, et al. Pulmonary regurgitation: the effects of varying pulmonary artery compliance, and of increased resistance proximal or distal to the compliance. Int J Cardiol 2009;133:157-66.

50. Chaturvedi RR, Redington AN. Pulmonary regurgitation in congenital heart disease. Heart 2007;93:880-9.

51. Kilner PJ, Sievers B, Meyer GP, Ho SY. Double-chambered right ventricle or sub-infundibular stenosis assessed by cardiovascular magnetic resonance. J Cardiovasc Magn Reson 2002;4:373-9.

52. Geva T, Greil GF, Marshall AC, Landzberg M, Powell AJ. Gadolinium-enhanced 3-dimensional magnetic resonance angiography of pulmonary blood supply in patients with complex pulmonary stenosis or atresia: comparison with Xray angiography. Circulation 2002;106:473-8.

53. Nagendran J, Michelakis E. MRI: one-stop shop for the comprehensive assessment of pulmonary arterial hypertension? Chest 2007;132:2-5.
54. Coulden R. State-of-the-art imaging techniques in chronic thromboembolic pulmonary hypertension. Proc Am Thorac Soc 2006;3:577-83.

55. Devos DG, Kilner PJ. Calculations of cardiovascular shunts and regurgitation using magnetic resonance ventricular volume and aortic and pulmonary flow measurements. Eur Radiol 2010;20:410-21.

56. Wald RM, Powell AJ. Simple congenital heart lesions. J Cardiovasc Magn Reson 2006;8:619-31.

57. Piaw CS, Kiam OT, Rapaee A, Khoon LC, Bang LH, Ling $\mathrm{CW}$, et al. Use of non-invasive phase contrast magnetic resonance imaging for estimation of atrial septal defect size and morphology: a comparison with transesophageal echo. Cardiovasc Intervent Radiol 2006;29:230-4.

58. Valente AM, Sena L, Powell AJ, Del Nido PJ, Geva T. Cardiac magnetic resonance imaging evaluation of sinus venosus defects: comparison to surgical findings. Pediatr Cardiol 2007;28:51-6.

59. Salehian O, Schwerzmann M, Merchant N, Webb GD, Siu SC, Therrien J. Assessment of systemic right ventricular function in patients with transposition of the great arteries using the myocardial performance index: comparison with cardiac magnetic resonance imaging. Circulation 2004;110:3229-33.

60. Rutledge JM, Nihill MR, Fraser CD, Smith OE, McMahon CJ, Bezold LI. Outcome of 121 patients with congenitally corrected transposition of the great arteries. Pediatr Cardiol 2002;23:137-45.

61. Sundaram B, Kreml R, Patel S. Imaging of coronary artery anomalies. Radiol Clin North Am 2010;48:711-27.

62. Cheng Z, Wang X, Duan Y, Wu L, Wu D, Liang C, et al. Detection of coronary artery anomalies by dual-source CT coronary angiography. Clin Radiol 2010;65:815-22. 